mansasa

$1-1-2005$

\title{
Culture shift: carer empowerment and cooperative inquiry
}

Marjorie Lloyd

Glyndwr University, m.lloyd@bangor.ac.uk

Follow this and additional works at: http://epubs.glyndwr.ac.uk/chcr

Part of the Community Health Commons, Psychiatric and Mental Health Commons, and the Psychiatric and Mental Health Nursing Commons

Copyright $(\odot) 2005$, John Wiley and Sons. Metadata only available from this website, due to copyright rules. The article was originally published in the Journal of Psychiatric and Mental Health Nursing in 2005 , by John Wiley and Sons. The definitive version is available at http://dx.doi.org/10.1111/j.1365-2850.2004.00816.x and via the publishers website at http://www3.interscience.wiley.com

\section{Recommended Citation}

Lloyd, M., \& Carson, A. (2005) 'Culture shift: carer empowerment and cooperative inquiry'. Journal of Psychiatric and Mental Health Nursing, 12, 187-191

This Article is brought to you for free and open access by the Nursing, Medical Sciences and Health at Glyndwir University Research Online. It has been accepted for inclusion in Health Science by an authorized administrator of Glyndŵr University Research Online. For more information, please contact 


\title{
Culture Shift -Carer Empowerment and Co-operative Inquiry
}

\author{
Lloyd M RN BSc (Hons) \& Carson A PhD RN
}

Glyndwr University, Plas Coch Campus Mold road Wrexbam. LL11 2AW

Address for correspondence

Marjorie Lloyd Glyndwr postal point 20, Plas Coch Campus, Mold road Wrexham Ll11 2AW tel: 01978293581 fax 01978290008 email lloydm@glyndwr.ac.uk. 


\title{
Culture Shift - Carer Empowerment and Co-operative Inquiry
}

\begin{abstract}
Government policy has directed local services to address the needs of carers as a way of maintaining care in the community. This study was initiated to enable carers to develop an information pack based upon their identified needs. Co-operative inquiry, was the method used to ensure full participation of the carers. Group meetings were already in existence through a charity organisation which provides a carers support network. The first author participated in a number of carers group meetings. Co-operative inquiry was used to clarify a number of themes identified and reflective cycles ensured that those themes remained relevant. It was found that carers do want to be involved in their relative's care, not as passive recipients but as collaborative care providers. To do this they need to be fully informed of the processes of care provision. Carers need information that is relevant, easily accessible and obtainable in varying degrees of comprehension. This study suggests that a culture shift within mental health nursing is necessary if professionals are to recognise that a perceived lack of support may lead to a breakdown in relationships between the carer, the person being cared for and the professionals.
\end{abstract}

Key Words: Carers, Co-operative Inquiry, Nursing, Social Policy. 


\section{Introduction}

The Community Care Act (Department of Health 1990) was implemented to change the emphasis on caring for people who suffer disabling conditions such as mental illness from old institutionalised psychiatric hospitals to local community provision with the support of voluntary and paid carers. Even though carers' needs were later identified and recognised in the Carers Act 1995, there was little substance to this Act except in recognising that carers have needs too. Consequently, the Carers and Disabled Children Act 2000 (Department of Health 2001) has acknowledged that carers must also have those needs addressed if they are to continue within their role as carers in the community. The government, through developing this Act has recognised, albeit ten years later that without carers the NHS would be unable to sustain care in the community (Parker \& Clarke 2002). This paper will discuss a small research project that funded a local mental health charity to explore the needs of carers and develop an information pack to address those needs.

\section{Literature overview.}

Much of the research around carers needs are either focused towards carers of older people (Nolan et al 1998, Nolan et al 2003) or are mainly quantitative in method (Lelliott et al 2003). Although similarities may be found there is little research on the qualitative or specific needs of carers of adults with a severe and enduring mental illness (Ryan 2002). Politically, it maybe suggested that the recent focus on carers as a resource may have more to do with saving money, as the government embarks on a three- pronged policy of closing hospitals, reducing costs and increasing family involvement (Jones 2002). Moreover, this increase in carer involvement can also be seen as an erosion of professional involvement (Kirk \& Glendinning 1998). Carers are increasingly being expected to take on the role which professionals might other wise have carried out in an institutional setting. This potential erosion of the role of trained mental health staff may result in conflict and an "I know best" stance from professionals (Ronning 2002). This has also been identified by Pejlert (2001), whilst interviewing members of staff who were providing community care. They indicated that there might be a "culture conflict" between the professional culture and the culture within individual families. Barrowclough et al (2001) also found that carers would develop their own beliefs about their relative's illness and its duration without early intervention from professional services. This 
conflicting culture between professionals and carers is an issue that should not be ignored, as it will impact upon a person's care. Parker and Clarke (2002) suggest that carers and their disabled relatives are being polarised in their need for help and support because of this culture conflict with the professional services.

More recent research by Lelliott et al (2003) found that carers are expressing the need to feel involved in the care planing process. In addition they found that most carers wanted help with their role through information and support from the professionals. This is reinforced by the national service frameworks for adult mental health (National Assembly for Wales 2002).

In reviewing the literature it may be suggested that recent research is a direct result of policy driven activity in order to alleviate the concern by the government about a lack of acknowledgement of the carer's role. Furthermore it may also be suggested that recent research has addressed the needs of the professionals and their cultural background for evidence based practice as well as, if not more so, than the needs of the carers. To overcome cultural bias, the research framework must be culturally neutral if it is to properly address the needs of the carers. A framework that does not adhere to any particular methodology is Action Research. Within this framework Co-operative Inquiry was developed by Heron \& Reason (2001) to address cultural and spiritual imbalances between the views of the researcher and those being researched. They suggest that cooperative inquiry addresses this imbalance by doing research "with" rather than "on" people.

\section{Method}

\section{Co operative inquiry within the action research framework}

Action research can be best seen as a process rather than a particular methodology. Waterman et al (2001) define it as: "A period of enquiry that describes, interprets and explains social situations while executing a change intervention aimed at improvement and involvement. Its particular strength lies in the coupling of participation and research to action and change". (P11)

The key features of this research process are participation and change. In this study, there was a particular emphasis on the need for participation and ownership by carers. It 
was felt that the involvement of carers was essential in this process. While action research does not specify a particular methodological approach, and in order to ensure that the carer's voices were heard it was found that information could be collected within a co operative inquiry approach. Co operative inquiry is defined by Heron \& Reason (2001) as "a way of working with other people who have similar concerns and interests to yourself in order to understand your world make sense of your life and develop new and creative way of looking at things; and learn how to act to change things you may want to change and find out how to do things better." (P 179)

Heron \& Reason (2001) go on to say that Co operative inquiry involves four phases within the research process which can be repeated any number of times. The importance of these phases is that at each phase a reflective cycle occurs. These phases will be discussed in more detail when describing data collection and analysis.

\section{Data collection and analysis}

Phase one

This initial stage is where all those expressing an interest come together and decide a route that the research will take. Initially, a questionnaire was developed through a series of meetings with family support workers, who helped identify the key issues. An introductory letter was included explaining the activity and the role of the researcher. Further follow up meetings were also planned to gather more in depth suggestions from the carers. The questionnaire was designed as a preliminary tool for gathering information; a total of 40 questionnaires were sent to carers who attended 3 support groups. The sample of carers who participated in this study was a purposive or theoretical sample (Cormack 2000) in that it was a particular group of people that was required; carers of people who suffer from severe and enduring mental illness. For the purpose of this study carers are defined by the Department of Health (2001) as people over the age of 16 who care for a person but excludes paid carers and/or volunteer workers. The carer does not have to be a relative or living with the person they care for. However, less than 5\% returned them. Part of the reason for this was the technical language used in the questionnaires. Upon reflection it was agreed that the questionnaire had been fruitless as the carers were unable to articulate their needs and needed help in identifying what these were. This had been partially anticipated at the initial meetings and had resulted in planning more in-depth consultations. 


\section{Phase two}

In phase two time was spent gathering data, recording the process and clarifying outcomes (Heron \& Reason 2001). The first author attended 3 carers' group meetings, which were facilitated by a family support worker and a one-day national conference in the first 3 months. The time was spent listening and talking to carers and family support workers. The author made notes during these conversations but they were limited as the author was participating in the activity itself. No attempt was made to tape- record these conversations as it was felt that this could serve to put some distance between the participants and the researcher. While this may have cost some data to be 'lost', the researcher felt that the use of a tape recorder would limit the level of overall participation and could possibly have created a barrier between researcher and researched. When carrying out co- operative inquiry it is necessary for the researcher to become part of the process. Everyone who was participating in the group activities and the research became co-subjects and co-researchers. This participatory level was used in gathering information through dialogue with carers. On reflection this was a very useful approach to take as it allowed open free flow discussion of the world of a carer. The carers relaxed as there were no restrictions and their narratives emerged.

\section{Phase three}

This phase is where the researcher might become lost in the process and may be experienced as chaos (Heron \& Reason 2001). A return visit to the group meant that a further participatory level of co operative inquiry was undertaken to analyse the themes that emerged from the earlier dialogues. Unlike most data analysis techniques, this participatory method ensures that carers also validated the themes that emerged. In this research process both parties are 'co- researchers' and 'co- subjects'. Here, a process of reflective dialogue is undertaken, which can lead to new and creative ways of doing things better. Reflecting on this phase the carers found it useful to clarify their thoughts and ideas and to create some structure to identifying what their needs actually were, rather than being told by a professional. These themes are discussed later in this paper.

\section{Phase four}

This phase is then where co-researchers and co-subjects look at the findings and bring together an outcome report. (Heron \& Reason 2001) As well as analysing and developing 
themes, carers were also involved in the design of the pack. It was acknowledged early on that the design and construction of the pack, as well as the contents, had to be 'carer friendly' and that a pack designed by professionals could potentially put some participants off. In addition participants saw professional packs as liable to become outdated quickly and they wanted a pack that was both familiar but also easily updated by themselves. A library of books that are aimed specifically at carers is possibly a unique aspect of this resource. The library was organised around the main themes that emerged from the project. Rather than a huge amount of information, carers also expressed a need for basic introductory information leaflets. These were designed on an A4, two column, landscape design that could be easily replicated. The reason for this ease of design was so that carers could eventually design their own leaflets and contribute to the pack. This would also ensure that the pack was updated regularly and remain relevant.

\section{Coperative Inquiry: Ethical Issues}

This study had been undertaken by a researcher, who had been hired to consult with carers and jointly develop an information pack. There were no formal ethical committees to be negotiated. Nevertheless, all research carries an ethical component. In this particular case, it was important that all participants could be heard and their views respected. As well as an initial letter explaining the study, participants were aware of the researcher's professional background. The process itself involved carers having the final say in the construction of the information pack. This provided an additional validation stage. Participants were also informed that while they would not be involved in any publications arising from the research, a copy of any publication would be kept in the library.

\section{Results/Themes identified}

Heron \& Reason (2001) argue that the most significant validity of Co operative inquiry is that it is an inquiry method that empowers the participants. Because of the bottom up approach with total involvement and control by the subjects, forms of knowing familiar with the reflective process become transparent. These are "experiential knowing" the experience of the carers, "presentational knowing" the carers presentation of self, "propositional knowing" of what mental illness means for them and "practical knowinghow" to cope with their role. These ways of knowing become evident in each of the following themes identified by the carers as being important to them. This holistic 
approach to identifying informational needs is unique to this method of inquiry because unlike other pieces of research there is no professional focus to drive the research and the researcher becomes immersed subjectively in the study. The following themes formed the main findings of the project and consequently the structure for the new information pack.

\section{Statutory and voluntary agencies}

Carers were often confused about which agency provided what support. A leaflet was created to introduce carers to voluntary and statutory agencies, explain their main differences and provide a list of local and national agencies that may be useful. Another leaflet gave a brief list of who was who in the mental health services, explaining to carers the different roles within the multidisciplinary team. This theme relates to previous studies that identified that professionals may feel that informal carers are threatening their role. Alternatively professionals may not have the time to explain the structure of community care services to carers. (Parker \& Clarke 2002, Kirk and Glendining 1998)

\section{Understanding mental illness}

Many carers did not feel that they knew enough about their relative's illness. A common complaint was the use of jargon such as CBT, PSI and SMI. A few leaflets explaining common terminology, treatments and early warning signs were enough to explain common meanings in the professional world. Carers also wanted to know about what happened to their relatives when they went into hospital and what could they expect A book list was added to this section which has been purchased and is available in the resource centre. Barrowlcough et al (2001) and Ryan (2002) suggest that carers will find their own model and risk management techniques to help them care for their relative. If professionals are unwilling or unable to share their knowledge with carers then they must expect that conflicting views will ensue.

Another feature of this theme for carers was that they could not access help quickly in an emergency. A carer said that all she wanted was for someone to tell her what to do- not do it for her. A leaflet was created to explain what to do when someone self harmed or attempted suicide by overdose. Ryan (2002) found that carers and service users manage risk as well as the professionals. The difference for the carers was their lack of 
confidence in their ability to cope in a crisis. Some support from the professionals in what actions need to be taken would be helpful.

\section{The law and your rights}

Many carers said that they did not understand the law and when it should be used. They felt that when an emergency happens was not the right time to ask for a full explanation. A few leaflets were designed for this section on the legal aspects of mental health care. Carers are often asked to make decisions about their relatives care at highly emotive times which can be difficult for the carer to decide what is best for their relative. Furthermore, professionals may only have contact with the carers at times of crisis and may withhold information at these times for fear of breaking patient confidentiality (Parker \& Clarke 2002, Kellet \& Mannion 1999, Kirk \& Glendinning 1998). However, in excluding carers until a crisis occurs may reduce their collaboration and co-operation with professional staff. Carers do not want to be excluded from their relative's care but often feel helpless when a crisis occurs.

\section{Helping Yourself}

Many carers suffer from stress related illnesses as looking after a relative is unavoidably emotional and take a great deal of strength and courage (Woof et al 2003, Forbat 2002 DOH 2001). Getting the best for a relative can often mean carers neglecting themselves. Furthermore financial implications of caring are soon felt when carers having to give up work to look after a relative. This also leads to social isolation for the carer as well as the relative. (DOH 2001) Some leaflets were compiled to help the carer identify their own needs, recognise when they were stressed, and methods of coping with stress identified. Carers can identify that much of their stress is triggered by the feelings of loss and guilt and anger that their relative is suffering from an incurable illness. Acknowledging these feelings is not something that has been recognised as a need in supporting carers in the community (Forbat 2001) Instead professionals tend to focus upon organising practical support. (Kellet \& Mannion 1999). This unrecognised need may contribute to the carer's eventual ill health as they struggle to cope with their own feelings.

\section{Limitations/Discussion}

While general conclusions must be limited because of its size and purpose, it has shown that nursing research and practice are very close to each other in the way that 
clients/respondents can learn to help themselves with nursing support. There is an identified need, discussed earlier, for professional and carers to work more closely together. This project has provided a model of involvement or participation that can generate the right kind of information that carers need. It has also demonstrated that if both researchers and carers are involved in a genuine participatory process, the quality of information provided is enhanced.

Through recent developments in social policy there has been a greater encouragement for users of services to be more involved in the construction and provision of services. This same ethos can also be applied to research projects. Through a process of reflection and action, the research led to the production of a valuable social resource that was sensitive to the identified needs of carers and their culture as opposed to the culture of the professionals. This research project has taken the idea of participation and applied it to all parts of the research project from the beginning, through data collection and analysis to design of the finished product. Participation in nursing research has to be a two way process, where both researchers and those that they are trying to help are full participants in the research process. In a recent paper, one of the authors has suggested that the telling and sharing of narratives can enhance joint participation in the research process and can develop more democratic models of practice (Carson \& Fairbairn 2002). What this project has demonstrated is that research in nursing has to develop a more open dialogue with the researched and co-operative inquiry promises to do this.

\section{Conclusion}

This paper has outlined a small- scale research project that led to the provision of an information pack for carers of adults who suffer from a severe and enduring mental illness. A participatory dialogue between the researcher and carers was used to develop and validate this pack. Practitioners and researchers often take their bearings from within their own professional culture and use such resources as research paradigms and models of care. Users and carers of services, by contrast, live within an everyday culture and use such resources as everyday knowledge or common sense. In a real sense, both have knowledge and experience that could be shared and this could lead to a greater understanding between them. Practitioners, researchers, carers and users all share a common interest in caring; some are voluntary and some are professional. This research has shown that co-operative inquiry can help to bridge the gap between these two cultures and enhance communication between them. If we are really going to 'care in the 
community' we need to encourage a culture shift to new research paradigms, or forms of knowing, that involve all in the search for a better quality of life for those who suffer from mental illness. 


\section{$\underline{\text { References }}$}

Barrowclough C Hatton C Quinn J (2001) An investigation of models of illness in carers of schizophrenia patients using the illness perception questionnaire. British Journal Of Clinical Psychology $40371-385$

Carson A. M. \& Fairbairn GF (2002) "The Whole Story: Towards an Ethical Research Methodology" Nurse Researcher Vol. 10 No 1:15-29

Cormack D (2000) The Research Process in Nursing. $4^{\text {th }}$ Ed. Oxford. Blackwell Science. Department of Health (1990) The NHS and Community Care Act 1990. London. HMSO. Department of Health (2001) A Practitioners Guide to Carers Assessments under the Carers and Disabled Children's Act 2000. London. HMSO

Forbat L (2002) "Tinged with Bitterness": re-presenting stress in family care. Disability \& Society, vol. 17(7) pp759-768

Heron J Reason P (2001) The Practice of Co-operative Inquiry: Research "with" rather than "on" people. Ch.16 in Reason P \& Bradbury H. (Eds.) Handbook of Action Research London. Sage. Jones D. W. (2002) Myths, Madness and the family. The impact of mental illness on families. Hampshire. Palgrave.

Kellett U.M. Mannion J. (1999) Meaning in caring: reconceptualising the nurse-family carer relationship in community practice. Journal of Advanced Nursing 29(3) 697-703

Kirk S. Glendinning C. (1998) trends in community care and patient participation: implications for the roles of informal Carers and community nurses in the United Kingdom. Journal of Advanced Nursing $28(2) 370-381$

Lelliott P. Beevor A. Hogman G. Hyslop J. Lathlean J. \& Ward M (2003) Carers and users expectations of services - carer version (CUES-C): A new instrument to support the assessment of Carers of people with a severe mental illness. Journal of Mental Health 12, 2, 143-152

Nolan M. R.Grant G, Keady J (1998) Assessing Carers Needs A Practitioners Guide. Brighton Pavilion Publications.

Nolan M, Lundh U, Grant G, Keady J (2003) Partnerships in Family Care: understanding the caregiving career. Open University Press Maidenhead

National Assembly for Wales. (2002) Adult Mental Health Services. A National Service Framework. for Wales. Welsh Assembly Government.

Parker G Clarke H (2002) Making ends meet: do Carers and disabled people have a common agenda. Policy \& Politics vol. 30 no 3 pp347-359

Pejlert A (2001) Being a parent of an adult son or daughter with severe mental illness receiving professional care: parents narratives. Health and Social Care in the Community. 9(4), 194-204 
Ronning R (2002) In defence of care: The importance of care as a positive concept. Quality in ageingpolicy practice and research.vol3 (4)

Ryan T (2002) Exploring the risk management strategies of informal careers of mental health service users. Journal of Mental Health 11,1,17-25

Waterman H Tillen D Dickson $\mathrm{R}$ de Koning K (2001) Action Research: a systematic review and guidance for assessment. Health Technology Assessment 5 (23)

Wooff D, Schneider J, Carpenter J, Brandon T (2003) Correlates of stress in carers. Journal of Mental Health. 12,1,29-4 